Universidad de Lima

Escuela de Posgrado

Maestría en Derecho Empresarial

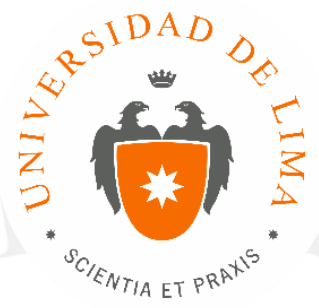

\title{
ALGUNOS ASPECTOS DEL ESTABLECIMIENTO DE SUCURSALES DE EMPRESAS EXTRANJERAS EN EL PERÚ
}

Trabajo de investigación para optar el Grado Académico de Maestro en

Derecho Empresarial

\section{Milagros Rabines Flores}

19912564

$$
\text { Lima - Perú }
$$

Marzo del 2016 


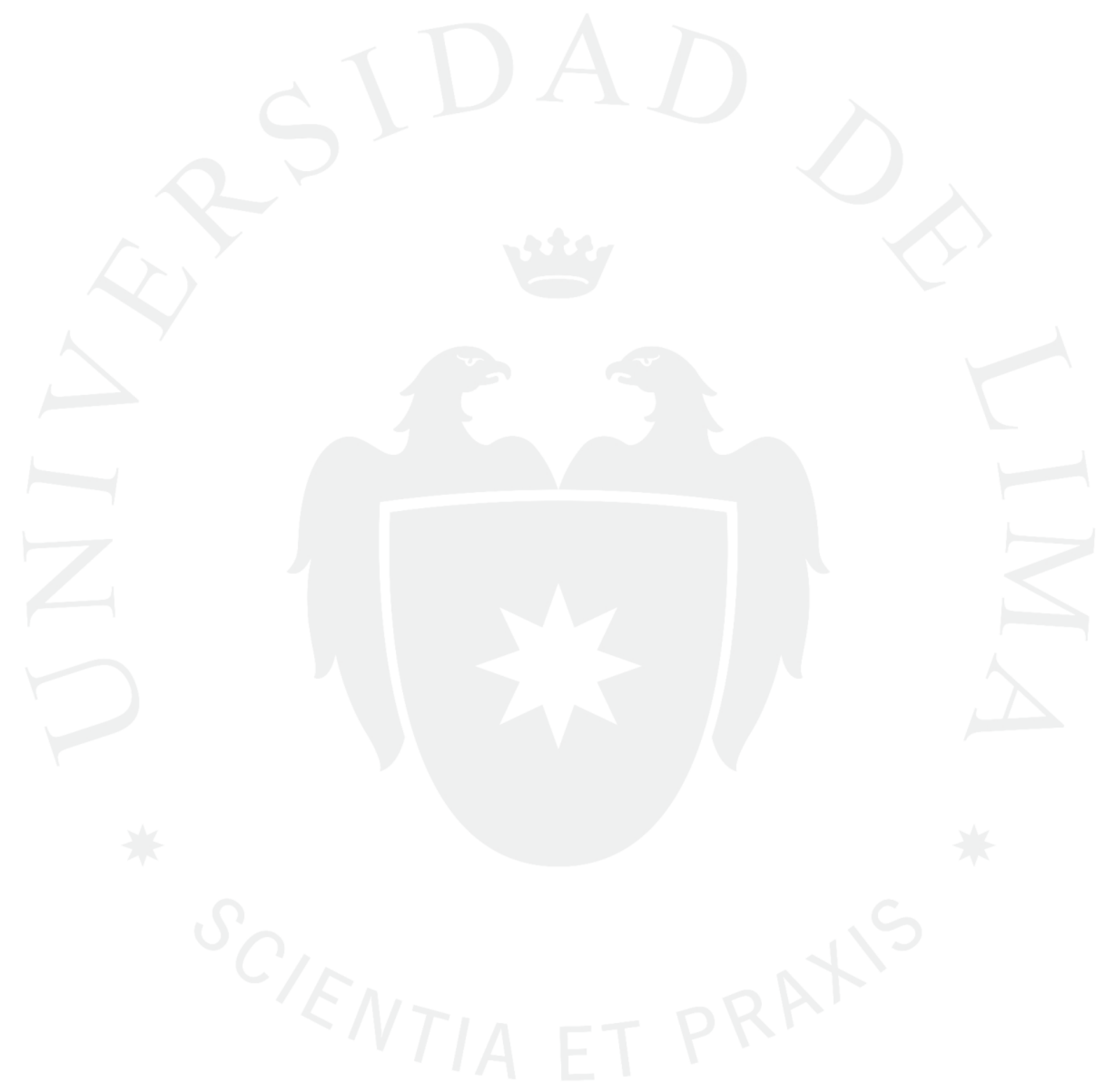




\section{ALGUNOS ASPECTOS DEL \\ ESTABLECIMIENTO DE SUCURSALES DE EMPRESAS EXTRANJERAS EN EL PERU}




\section{TABLA DE CONTENIDO}

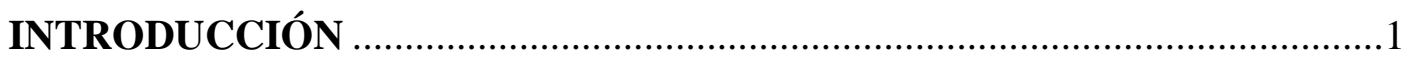

CAPÍTULO I: GENERALIDADES SOBRE LAS SUCURSALES ...................2

1.1 ¿Por qué establecer una sucursal ........................................ 2

1.2 ¿Qué es una sucursal?................................................. 3

1.3 Concepto y requisitos según la legislación peruana .....................5

1.3.1 Capital Asignado ......................................................... 7

1.3.2 Actividades que son parte del objeto social .......................... 7

1.3.3 Domicilio ................................................................... 8

1.3.4 Designación del representante legal permanente y poderes que se le

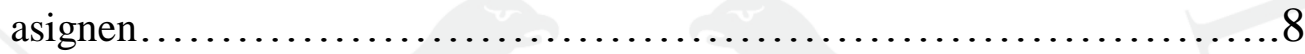

1.3.5 Sometimiento a las leyes del Perú ...................................... 8

CAPÍtULO II: ALGUNAS CONSIDERACIONES DERIVADAS DE SU

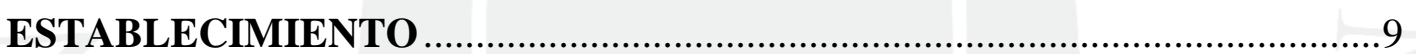

2.1 Sobre el capital asignado ................................................ 9

2.2 Sobre el domicilio y denominación .................................... 12

2.3 Sobre el representante legal permanente ............................. 15

2.4 Sobre el sometimiento de la matriz a las leyes del Perú ................. 20

2.5 Sobre la reorganización de la sucursal................................. 22

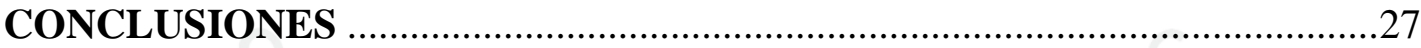




\section{INTRODUCCIÓN}

Para delimitar el campo de estudio, es preciso señalar que el presente trabajo solo abarca el establecimiento de sucursales de empresas extranjeras en el Perú.

Consideramos que las sucursales constituyen una importante herramienta para la promoción de la inversión privada extranjera en nuestro país, sin embargo las diferentes interpretaciones que los operadores del derecho le confieren a la diversa terminología legal que se utiliza en este campo, genera confusión y por ende retraso en los procesos de establecimiento de las sucursales o incluso como veremos, también diferenciación no establecida en la ley respecto de actividades de contratación, exigiendo a la sucursal requisitos no contemplados en la norma, siendo por ello necesario mediante este documento tratar de aclarar tales conceptos en aras de simplificar los procesos de inscripción de las sucursales, generar seguridad jurídica a los terceros locales que se relacionen con estas y a la vez hacerlas atractivas para el inversionista extranjero. 


\section{CAPÍTULO I: GENERALIDADES SOBRE LAS SUCURSALES}

\section{1 ¿Por qué establecer una sucursal}

La mayor demanda de productos o servicios que desarrolla una empresa, la penetración de esos productos o servicios a otros mercados, la reducción de costos, la maximización de ganancias, el deseo de ser más competitiva; todas estas son razones por las cuales la proyección de una empresa en otras zonas geográficas puede ser atractiva; y todas ellas sustentan igualmente la globalización de la economía.

La globalización de la economía genera que la actividad comercial se extienda a otros mercados y esa necesidad de extensión, de proyectar la empresa a otras ciudades, de trascender fronteras, pero a través de figuras jurídicas que les permitan responder a una estrategia común y, como diría Reaño Azpilcueta (2010, p. 23) a una sola dirección organizativa, da lugar al establecimiento de sucursales.

La respuesta a la pregunta de por qué establecer una sucursal, como veremos a través de este desarrollo es: el deseo empresarial de expandirse a nuevas zonas geográficas.

No obstante, cada país ofrece distintas alternativas o mecanismos legales para implementar una decisión de esta naturaleza. Podríamos así hablar de sucursales, filiales o subsidiarias y demás formas jurídicas que ofrezca cada país.

En efecto, la ampliación de horizontes se puede realizar a través de filiales o subsidiarias, que son empresas independientes en las cuales una parte del capital y, por ende, de las acciones, pertenecen a la empresa principal o matriz. Esto implica que las filiales sean entidades con personería jurídica distinta de la matriz, con capital propio y que sus actividades puedan ser similares o distintas de aquellas que realiza la principal, además poseen nombre, domicilio y personalidad independiente de la sociedad principal ("Sucursales y las filiales", 2015). No obstante, de alguna manera esa independencia es relativa ya que, esta figura jurídica no deja de ser un mecanismo societario de extensión de fronteras para la principal o matriz la que, en función de su participación en el accionariado tendrá mayor o menor poder y control sobre la filial o subsidiaria. 
A diferencia de la sucursal, cuya definición se encuentra recogida en nuestra Ley General de Sociedades (Ley $N^{\circ} 26887,1997$ ) como veremos más adelante, no existe en nuestra legislación societaria una definición de filial o subsidiaria, sin embargo, es claro que se trata de empresas con participación mayoritaria de una principal. La Ley General del Sistema Financiero y del Sistema de Seguros, y Orgánica de la Superintendencia de Banca y Seguros, Ley $N^{\circ} 26702$ (1996), prevé por ejemplo que determinadas actividades de las empresas del sistema financiero deban necesariamente desarrollarse a través de subsidiarias. La referida Ley no las define, sin embargo, establece algunos requisitos para su establecimiento y los porcentajes de participación en la subsidiaria, como por ejemplo, un mínimo de 3/5 partes del accionariado de la subsidiaria ${ }^{1}$.

En resumen, las subsidiarias y filiales son empresas constituidas en el Perú, dotadas de personería jurídica. La sucursal en cambio no tiene personería jurídica. A decir de Castle Álvarez (2005) es el vehículo que el Derecho Societario le da a la empresa para domiciliarse empresarialmente en lugares distintos de la principal; pero, en todos los casos son una extensión de la sociedad extranjera que a través de esta figura jurídica busca tener control y extender sus horizontes (p. 1230).

\section{$1.2 \quad$ ¿Qué es una sucursal?}

Para Cabanellas (como se citó en Beaumont Callirgos. 2001), la sucursal es:

El establecimiento mercantil o industrial que depende de otro, llamada central o principal, cuyo nombre reproduce, ya esté situado en distinta población o en barrio distinto de una ciudad importante ... las sucursales mantienen la unidad de firma social, no poseen capital propio ni responsabilidad separada, aunque puedan gozar

\footnotetext{
${ }^{1}$ Artículo 224.- OPERACIONES REALIZABLES A TRAVÉS DE SUBSIDIARIAS

Para que las empresas del sistema financiero realicen las siguientes operaciones, deben constituir subsidiarias:

a) (Derogado)

b) Operar como almacenes generales de depósito;

c) Actuar como sociedades agentes de bolsa, sujetándose a la Ley del Mercado de Valores;

d) Establecer y administrar programas de fondos mutuos y de fondos de inversión, sujetándose a la Ley del Mercado de Valores;

e) Operar como Empresas de Custodia, Transporte y Administración de Numerario y Valores, siempre que cuente con autorización de la Superintendencia, del Ministerio del Interior y de la Comisión Nacional Supervisora de Empresas y Valores - CONASEV;

f) Actuar como fiduciarios en fideicomisos de titulación, sujetándose a lo dispuesto en la Ley del Mercado de Valores.

Una misma subsidiaria no puede desarrollar más de una de las operaciones o actividades reseñadas en los numerales 1 al 6 que anteceden. También pueden constituir subsidiarias para realizar las demás operaciones indicadas en el artículo 221, así como constituir como subsidiarias a las Empresas Administradoras Hipotecarias, según lo establecido en la ley que rige a estas últimas."
} 
de relativa independencia dentro de la estructura interna de la institución. Sus jefes son gerentes con mayores o menores atribuciones. Llevan contabilidad especial que luego se resume en la general del establecimiento. Las sucursales integran especie de colonias o bases económicas de las grandes empresas, cuyas instrucciones y suministros proceden por lo común y exclusivamente de la casa central o matriz. (p. 84)

Por su parte, Echaiz Moreno (2012) la define como "un brazo mediante el cual la sociedad extiende su campo de actuación empresarial" (p. 62).

$\mathrm{Al}$ respecto, Etcheverri (como se citó en Beaumont Callirgos, 2001) señala que:

Casa matriz y sucursal son establecimientos distintos pero que tienen un solo patrimonio y una misma administración; únicamente se desenvuelven en ámbitos espaciales distintos por razones de descentralización. Al frente de la sucursal estará un factor de comercio ... La contabilidad de la sucursal forma parte de la contabilidad central, con cierta descentralización momentánea, que después se vuelca en un total. No tiene la sucursal patrimonio ni personalidad propios; lleva el nombre de la empresa principal; tiene un domicilio especial a causa de la necesidad de descentralización que la creó. (p. 85)

A decir de Flury (2009) la sucursal es:

Un establecimiento permanente de una sociedad a la que se le puede confundir como una sociedad independiente y no accesoria, que existe dentro de otra que es la sociedad principal, por cuanto ambas están ubicadas en un domicilio distinto donde desarrollan sus actividades empresariales, y ambas tienen administración propia, constante y debidamente facultada para comprometerlas en las actividades comerciales que desarrollan y para asumir las responsabilidades emergentes de los actos que ejecutan ... [en resumen es] un establecimiento independiente, con autonomía de gerencia, que será administrado por el representante legal permanente, quien actúa conforme a las facultades que le otorgan la ley, los estatutos de la sociedad principal y el acta de establecimiento de la sucursal. (pp. $52-53)$

Refiriéndose a las sucursales, Rodríguez (como se citó en Tori Vargas. 2006) señala que debe tratarse de locales en los que se concluyan negocios jurídicos que constituyan la actividad base de la negociación; debe gozar de una cierta independencia 
jurídica y económica; y, debe estar subordinada a la alta dirección de la casa matriz en el sentido que esta pueda dar instrucciones a aquella (p. 308).

Elías (como se citó en Castle Álvarez, 2005) señala que las sucursales son establecimientos secundarios en la medida en que mantienen un nivel de subordinación administrativa respecto de la principal (p. 1241).

Tomando las definiciones de los citados autores tenemos que una sucursal es un establecimiento secundario de la empresa que desarrolla actividades económicas en el marco del objeto social de la sociedad principal o matriz, en un lugar distinto al domicilio de su principal. Asimismo, refieren, que la sucursal es un brazo de la principal por lo que no tiene personería jurídica propia y cuenta con un representante legal facultado para actuar con autonomía de gestión dentro de los límites que la principal le imponga.

\subsection{Concepto y requisitos según la legislación peruana}

Las sucursales en nuestra legislación, se encuentran definidas en el artículo 396 de la Ley $N^{\circ}$ 26887, Ley General de Sociedades. De conformidad con dicha ley, se define a la sucursal como: "todo establecimiento secundario a través del cual una sociedad desarrolla, en lugar distinto a su domicilio, determinadas actividades comprendidas dentro de su objeto social. La sucursal carece de personería jurídica independiente de su principal. Está dotada de representación legal permanente y goza de autonomía de gestión en el ámbito de las actividades que la principal le asigna, conforme a los poderes que otorga a sus representantes."

Hundskopf (2015, pp. 232-233) destaca 8 aspectos de las sucursales según el citado artículo 396:

- Primero que la sucursal es un establecimiento secundario, lo que conlleva a decir del autor un nivel de subordinación administrativa.

- Segundo, que cuenta con un domicilio distinto al de su principal.

- Tercero que la sucursal desarrolla las mismas actividades empresariales que son realizadas por la principal.

- Cuarto, tiente personaría jurídica independiente pues es una proyección jurídica de una sociedad, no tiene vida propia y no es por si misma sujeto de derechos y obligaciones 
- Quinto, carece de denominación propia pues adquiere por el acto de su constitución la denominación de su principal.

- Sexto, tienen estabilidad y permanencia a través de un representante legal que se hace responsable de sus operaciones y obligaciones.

- Séptimo, tiene autonomía de gestión, lo cual significa que puede adoptar decisiones en la misma sucursal siempre que se encuentren enmarcadas dentro del ámbito de actividades autorizadas por la matriz.

- Octavo, el representante legal permanente se rige por las normas establecidas para el gerente general de una sociedad en cuanto resulten aplicables.

- Para que esta figura jurídica funcione, la ley exige que su establecimiento conste por escritura pública y ésta se inscriba en Registros Públicos, además del cumplimiento de una serie de requisitos de forma taxativos para su inscripción, los mismos que se encuentran comprendidos en el artículo $403^{\circ}$ de la citada Ley General de Sociedades y que detallamos a continuación:

1. El certificado de vigencia de la sociedad principal en su país de origen con la constancia de que su pacto social ni su estatuto le impiden establecer sucursales en el extranjero;

2. Copia del pacto social y del estatuto o de los instrumentos equivalentes en el país de origen; $y$,

3. El acuerdo de establecer la sucursal en el Perú, adoptado por el órgano social competente de la sociedad, que indique: el capital que se le asigna para el giro de sus actividades en el país; la declaración de que tales actividades están comprendidas dentro de su objeto social; el lugar del domicilio de la sucursal; la designación de por lo menos un representante legal permanente en el país; los poderes que le confiere; y su sometimiento a las leyes del Perú para responder por las obligaciones que contraiga la sucursal en el país.

4. Es este último requisito, consistente en el acuerdo del órgano social competente de la matriz, el que nos ocupará en adelante. 


\subsubsection{Capital Asignado}

Según señala Castle Álvarez (2005) el Capital Asignado es la provisión de fondos que le entrega, otorga o asigna la principal a la sucursal para su establecimiento y funcionamiento. Este nada tiene que ver con el capital social de la sociedad desde un punto de vista jurídico, pues no genera acciones, participaciones, títulos o similares, ni tampoco derechos o, limitaciones sobre la base de él. Es simplemente el capital de trabajo que se entrega para que se funde y funcione la entidad (pp. 1259-1260).

De otro lado, encontramos la Resolución del Tribunal Registral $N^{\circ}$ 124-2001ORLC/TR, la cual define al capital asignado como la dotación económica que la principal asigna y que responde a una verdadera dotación patrimonial.

Para fines económicos, financieros y contables, sin embargo, dicho capital, por su naturaleza, constituye el patrimonio de la sucursal en tanto será base para medir y establecer los beneficios o pérdidas que resulten del desarrollo de las actividades de la sucursal.

Cabe señalar que el concepto de "capital asignado" es propio y exclusivo de las sucursales de sociedades no domiciliadas, pues se encuentra establecido en la Ley General de Sociedades (Ley $\mathrm{N}^{\circ}$ 26887) únicamente para estas y no para las sucursales de empresas constituidas en el Perú. Tampoco debe ser confundido con el concepto "capital social" que se utiliza para las empresas constituidas en el país, tema que trataremos más adelante en el presente estudio.

\subsubsection{Actividades que son parte del objeto social}

El objeto social, que determina los límites dentro de los cuales realiza sus actividades la principal o matriz, se extiende, a través de este brazo denominado sucursal (Echaiz Moreno, 2012, p.62).

Según Flury (2009) la sucursal, como parte integrante de la sociedad principal, tiene por objeto social el mismo que esta y no podrá dedicarse a realizar actividad ajena a tal parámetro (p. 94). En este mismo sentido nuestra legislación ha establecido como requisito para la inscripción de la matriz que el acuerdo emitido por el órgano de gobierno competente de ésta, contenga la declaración de que las actividades que realizará la sucursal están comprendidas dentro de su objeto social. 


\subsubsection{Domicilio}

El profesor español Marina (como se citó en Beaumont Callirgos, 2001) refiere que:

El domicilio es un concepto fundamental para el Derecho. La persona requiere siempre de un lugar determinado para ejercer el contenido de su posición jurídica, a saber, para ejecutar sus derechos y cumplir sus obligaciones. Las relaciones jurídicas serían especialmente precarias sin la existencia del domicilio. (p. 88)

En general, domicilio debe ser entendido como la zona geográfica, es decir la ciudad, provincia o departamento que sirve de lugar de instalación y ubicación de una sociedad (Castle Álvarez, 2005, p. 1238)

Para el caso de sucursales, al referirse la Ley al domicilio se está refiriendo a lugar designado por el órgano social para el desarrollo de las actividades que le han sido asignadas, el cual debe estar ubicado, casi como consecuencia lógica, en un domicilio distinto al de la principal.

\subsubsection{Designación del representante legal permanente y poderes que se le asignen}

Según establece el Artículo 399 de la Ley General de Sociedades (Ley N²6887), el acuerdo de establecimiento de la sucursal contiene el nombramiento del representante legal permanente que goza, cuando menos, de las facultades necesarias para obligar a la sociedad por las operaciones que realice la sucursal y de las generales de representación procesal que exigen las disposiciones legales correspondientes. Las demás facultades del representante legal permanente constan en el poder que se le otorgue. Para su ejercicio, basta la presentación de copia certificada de su nombramiento inscrito en el Registro.

\subsubsection{Sometimiento a las leyes del Perú}

La Ley General de Sociedades (Ley $N^{\circ}$ 26887) exige que en el acuerdo de la matriz para el establecimiento de la sucursal conste su sometimiento a las leyes del Perú para responder por las obligaciones que contraiga la sucursal en el país. El sometimiento al que se refiere la ley es de la matriz o principal como veremos en el siguiente capítulo. 


\section{CAPÍTULO II: ALGUNAS CONSIDERACIONES DERIVADAS DE SU ESTABLECIMIENTO}

Entre los requisitos exigidos por la Ley General de Sociedades (Ley $\mathrm{N}^{\circ} 26887$ ), para el establecimiento de una sucursal, hay algunos que pasaremos a comentar pues, si bien son similares a los correspondientes a las demás modalidades societarias comprendidas en la citada Ley, adquieren connotaciones distintas o diferenciadas específicamente para el caso de las sucursales.

\subsection{Sobre el capital asignado}

Como vimos en el capítulo precedente, el capital asignado es la provisión de fondos que le entrega, otorga o asigna la principal a la sucursal para su establecimiento y funcionamiento. No existe un título representativo que lo acredite ya que la ley no lo exige (como sí ocurre con el capital social de una sociedad anónima, por ejemplo, que está representado por acciones). El único documento en el que se refleja el capital asignado, es el acuerdo adoptado por el órgano competente de la matriz que lo asigna.

Se asume que este capital es entregado a la sucursal para el inicio de sus actividades en el territorio nacional y ello sustenta que se indique el valor de los recursos que formarán parte de dicho "capital". No obstante, tal como señala Flury (2009):

Esta asignación de capital no es de manera alguna una segregación o división del capital original de la propia sociedad principal extranjera y no domiciliada. Tampoco supone una remesa física desde el extranjero de una cantidad de dinero que formará el capital asignado a la sucursal creada para operar en el país. (pp. 78-79)

Esto significa que, en la práctica, y dado que no es obligatorio que el dinero se encuentre físicamente en el país, se pueden presentar los siguientes escenarios: que la matriz traslade a la sucursal el patrimonio que representa dicho capital, que lo haga parcialmente o que no traslade fondo alguno (aunque este escenario en la práctica es poco probable pues la sucursal no tendría cómo dar inicio a sus actividades).

La errada asimilación del concepto de capital social al de capital asignado ha generado diversos errores de interpretación. Claro ejemplo de ello se verifica en los casos 
de los comités especiales del Ministerio de Transportes y Comunicaciones que citan Estrada y Olórtegui (2012, p. 333) en los que, a través de las consultas a las bases de los distintos procesos de selección, se verifica que se adoptó como criterio (errado) para verificar el cumplimiento del requisito consistente en la acreditación de la capacidad económica del postor, la tendencia a exigir que no solo las sociedades constituidas en el Perú acrediten un capital social suscrito y pagado, sino además que dicho requisito sea, de alguna manera, exigible a las sucursales de las empresas extranjeras o a las empresas extranjeras no domiciliadas en el Perú, bajo el sustento de requerirse acreditar capacidad económica; a pesar de que el requisito de capital "social", "suscrito" y "pagado" en el Perú solo puede corresponder a sociedades constituidas en el Perú.

Evidentemente, no será posible acreditar capital suscrito y pagado, si no nos encontramos ante la figura de un capital social en la medida que, estas empresas no emiten acciones y no poseen "capital social” sino "capital asignado", el mismo que no permite su suscripción. Básicamente se pide un imposible jurídico que además va directamente en contra de lo regulado por el artículo 152 de la Resolución No 200-2011 - SUNARP que aprueba el Reglamento del Registro de Sociedades y que expresamente señala que, no es necesario acreditar el capital "asignado" de una sucursal de una sociedad extranjera ante Registros Públicos.

Como podemos apreciar, este error ha generado que en más de una ocasión las empresas extranjeras establecidas como sucursales en el Perú, hayan recibido un trato, si se quiere discriminatorio, que ha terminado en su exclusión de los procesos de contratación con el Estado, perjudicando así no solo a la sucursal retirada del concurso, sino también por qué no, de manera potencial al propio Estado, al retirar de la competencia a uno o más postores que podrían haber ofrecido condiciones más favorables.

Este desarrollo sustenta que, entre los requisitos de inscripción de una sucursal de sociedad extranjera ante Registros Públicos, se exija el acta del órgano societario competente de la matriz o principal mediante el cual se establezca el monto de su capital "asignado", no siendo necesario que se acredite que se ha depositado el monto de dicho capital.

No obstante, esta situación respecto del capital asignado para darle o "asignarle" a la sucursal un capital que le permita realizar sus operaciones en el marco del objeto 
social de la principal o matriz, tiene efectos contables pues la sucursal reportará dinero por los bienes que le son asignados.

Sin lugar a dudas, la asignación de un capital a la sucursal es importante como garantía para los acreedores, a pesar de que su eficacia como tal sea relativa dada la posibilidad de no tener que acreditarlo al momento de establecerse en el Perú.

Es difícil entender cómo el capital puede resultar en una garantía para los acreedores locales y, facilitar las operaciones de una sucursal si no se cuenta con dicho patrimonio en el Perú. Cómo podría así protegerse los derechos económicos para la recuperación de créditos de terceros ante un incumplimiento de la sucursal. Ello, sin perjuicio del hecho de que, como señala Flury (2009), al constituir ambas una sola unidad patrimonial, la sociedad principal mantiene la responsabilidad por todos los actos de su sucursal, respondiendo con todos los bienes que conforman su patrimonio (p. 77). De ahí la importancia de la declaración inserta en la escritura de establecimiento de la sucursal, de someter a la principal a las leyes del Perú, tema que analizaremos más adelante.

De esta manera, coincidimos hasta cierto punto con el citado autor cuando considera que el capital asignado a una sucursal representa seguridad para los terceros que contraten con ésta, y una garantía de que existirá respaldo para hacer frente a las obligaciones que contraiga la sucursal en el país por el desarrollo de la actividad económica que ejecute.

No obstante, nos parece cuestionable que este patrimonio se constituya en garantía "inmediata o automática" para los acreedores pues, esta "garantía" no necesariamente permanece inmóvil y más aún los fondos no necesariamente se encontrarán en el país. Ciertamente, de que se encuentren o no en el país dependerá el mayor o menor costo para el acreedor afectado que busque exigir tal cumplimiento.

Lo expuesto conlleva a que el aumento o la disminución del capital asignado resulte hasta cierto punto indiferente para garantizar en mayor o menor medida el cumplimento de las obligaciones frente a terceros acreedores. En la práctica, rara vez se ha verificado el aumento o la disminución del capital asignado de una sucursal.

Cabe señalar que ninguna de las disposiciones que regulan a las sucursales establecen que el capital asignado deba constar en efectivo, con lo cual, esta asignación podría efectuarse en dinero o en especie. En este último caso, tampoco se exige acreditar la entrega del bien o bienes materia de asignación con lo cual nos encontramos en la 
misma situación comentada sobre eficacia real de la garantía para los acreedores ante el incumplimiento.

\subsection{Sobre el domicilio y denominación}

Castle Álvarez (2005) define el domicilio de la sucursal como el lugar designado por el órgano social para el desarrollo de las actividades que le han sido asignadas, el que debe estar en un domicilio distinto al de la principal (p. 1238).

El acuerdo del órgano social competente de la matriz debe incluir entre otros la fijación del domicilio, el que de conformidad con el artículo 20 de la Ley General de Sociedades (Ley $\mathrm{N}^{\circ}$ 26887) es el lugar, señalado en el estatuto, donde desarrolla alguna de sus actividades principales o donde instala su administración. Como bien señala Castle Álvarez (2005), el domicilio de la sociedad es

La zona geográfica, es decir la ciudad, provincia o departamento que sirve de lugar de instalación y ubicación de una sociedad. Es el lugar donde está la sede social; donde se reúnen sus órganos sociales y de administración; se realizan y formalizan los actos de publicidad registral; se determina la competencia judicial contencioso administrativa, tributaria y similares. (p. 1238)

Cabe detenerse en este punto pues, para efecto de las sucursales es importante considerar que, de conformidad con las disposiciones que las rigen al establecerse, se declara expresamente que las actividades que realizarán serán aquellas que correspondan al objeto social de la matriz por lo que, desde nuestro punto de vista, el establecimiento de una sucursal para la realización de actividades netamente administrativas o distintas de aquellas comprendidas en su objeto social no parecería válido.

De otro lado, el artículo 21 de la Ley General de Sociedades (Ley $\mathrm{N}^{\circ}$ 26887), establece que "La sociedad constituida y con domicilio en el extranjero que desarrolle habitualmente actividades en el Perú puede establecer sucursal u oficinas en el país y fijar domicilio en territorio peruano para los actos que practique en el país. De no hacerlo, se le presume domiciliada en Lima."

No vemos la aplicabilidad de la presunción contenida en este artículo en la práctica pues, bajo el esquema en el que opera una sucursal, no será posible que se establezca si el domicilio no se ha fijado en el acuerdo que será inscrito en los Registros Públicos, de conformidad con lo establecido en el artículo 403 de la Ley $\mathrm{N}^{\circ} 26887$. En un 
supuesto tal, el título registral seria materia de observación por incumplir con un requisito de forma; sin perjuicio de que subsanable, el hecho es que en la práctica la presunción no aplica, pues es obligatorio por mandato legal señalar el domicilio. Más aun, se evidencia una contradicción entre lo establecido en el artículo 21 y 403 de la Ley pues por un lado establece la asignación de domicilio como requisito para el establecimiento de la sucursal y, por otro lado, establece que si no se señala se presume Lima.

El único supuesto en el que podría aplicar la presunción sería uno en el que la sucursal hubiera realizado algún acto con anterioridad a su inscripción, cuando no se hubiera fijado domicilio; sin embargo, aun en ese caso se presenta una situación de arbitrariedad en la aplicación de la presunción pues las sucursales de empresa extranjeras no necesariamente se establecen en Lima.

Otro aspecto importante a considerar es que la Ley no ha establecido restricción alguna respecto del número de sucursales que se puede establecer en el país. En ese sentido es posible que una sociedad extranjera establezca varias sucursales:

No existe prohibición alguna en las normas mercantiles ni hay impedimento legal para que una misma sociedad domiciliada o no, pueda formar varias sucursales. Cada una de ellas deberá actuar en domicilio distinto, no pudiendo coincidir dos en un solo domicilio social. (Flury. 2009, p. 67).

En efecto, en la medida que se trate de distinta zona geográfica, es posible establecer sucursales en diversos espacios geográficos (departamentos, provincias o regiones) del Perú para el funcionamiento de una sociedad extranjera. Así, por ejemplo, podría establecerse una sucursal de empresa extranjera en Lima y otra en Iquitos.

Tanto el artículo $29^{\circ}$ del Reglamento del Registro de Sociedades aprobado por Resolución del Superintendente Nacional de los registros Públicos $N^{\circ}$ 200-2001SUNARP-SN ${ }^{2}$ como el artículo $30^{\circ}$ del Reglamento de Inscripciones del Registro de Personas Jurídicas aprobado por Resolución del Superintendente Nacional de los Registros Públicos № 038-2013-SUNARP-SN³ , hacen referencia al domicilio de la sucursal.

\footnotetext{
${ }^{2}$ Artículo 29.- Domicilio

En el asiento de inscripción del pacto social, del establecimiento de sucursal, o de sus modificaciones, deberá consignarse como domicilio una ciudad ubicada en territorio peruano, precisándose la provincia y departamento a que dicha ciudad corresponde.
}

${ }^{3}$ Artículo 30.- Nombre de las sucursales 
El primero establece que, en el asiento de inscripción del pacto social, del establecimiento de sucursal, o de sus modificaciones, deberá consignarse como domicilio una ciudad ubicada en territorio peruano, precisándose la provincia y departamento a que dicha ciudad corresponde. En el segundo se establece que, para su inscripción, las sucursales de las personas jurídicas deberán tener el mismo nombre que su principal y añadir el término sucursal, con indicación del domicilio de la sucursal.

Con ello, de alguna manera se complementa la delimitación de la zona geográfica pues, evidentemente, el registro público no admitirá la inscripción en una misma zona registral de dos sucursales bajo la misma denominación.

A propósito de la denominación cabe recordar que la inexistencia de personería jurídica propia o independiente de la principal, es el sustento para que la sucursal no tenga una denominación propia, sino que incluso su denominación sea una extensión de su principal, pues en la sucursal y principal se identifica al mismo sujeto de derechos, lo que se refleja igualmente en la denominación.

Esto puede generar ciertos problemas para las sociedades extranjeras que desean establecer sucursales en el país cuando, al iniciar el proceso de establecimiento e inscripción, verifican la existencia de una sociedad peruana inscrita con la misma denominación.

El artículo $16^{\circ}$ del Reglamento (Resolución SUNARP N²00-2001) establece que "se entiende que existe igualdad cuando hay total coincidencia entre una denominación o una razón social con otra preexistente en el índice, cualquiera sea la forma societaria adoptada.

También existe igualdad, en las variaciones de matices de escasa significación tales como el uso de las mismas palabras con la adición o supresión de artículos, espacios, preposiciones, conjunciones, acentos, guiones o signos de puntuación; el uso de las mismas palabras en diferente orden, así como del singular y plural.

Cuando el registro del nombre de la sociedad peruana preexiste al de la sociedad extranjera parecería quedar claro el derecho de inscripción de la primera y la imposibilidad de registro del nombre de la sociedad extranjera como sucursal; sin

Para su inscripción las sucursales de las personas jurídicas deberán tener el mismo nombre que su principal y añadir el término sucursal, con indicación del domicilio de la sucursal. En este caso no es de aplicación lo dispuesto en el artículo 28 de este Reglamento. 
embargo, como señala Castle Álvarez (2005), el problema se presenta respecto de una sociedad extranjera cuya denominación haya preexistido a la sociedad peruana con cuya denominación se identifica, refiriéndose específicamente al caso de una sociedad extranjera reconocida en su país, región o en el mundo (p. 1246). En este caso, es posible acudir a las instancias administrativas de protección de propiedad industrial, Instituto Nacional de Defensa de la Competencia y de la Protección de la Propiedad Intelectual (Indecopi), para discutir el derecho de registro ante dicha institución; discusión que se puede extender a nivel judicial con la finalidad de lograr una eventual inscripción en los Registros Públicos, obligando de este modo a la empresa peruana a cambiar de denominación social.

Sin perjuicio de ello, la salida que vemos como viable para efectos de la inscripción registral o formalización en el Perú de la sociedad extranjera es a través de la constitución de una filial o subsidiaria.

El hecho es que, para efectos del establecimiento de la sucursal en el marco de esa figura jurídica, es decir, la de sucursal, habrá una limitación siempre que ya exista inscrita en los Registros Públicos una denominación igual o similar bajo los términos de la Ley, situación que puede ser prevista mediante la previa búsqueda registral de la denominación social en los Registros Públicos.

\subsection{Sobre el representante legal permanente}

El Artículo $399^{\circ}$ de la Ley General de Sociedades (Ley $\mathrm{N}^{\circ}$ 26887), establece que el acuerdo de establecimiento de la sucursal contiene el nombramiento del representante legal permanente que goza, cuando menos, de las facultades necesarias para obligar a la sociedad por las operaciones que realice la sucursal y de las generales de representación procesal que exigen las disposiciones legales correspondientes.

Tal como señala Hundskopf (2015) las sucursales tienen estabilidad y permanencia a través de un representante legal, pues se crean para desarrollar el negocio en un lugar lejano al domicilio social, para lo cual necesitan un representante legal que se haga responsable de sus operaciones y obligaciones (p. 233).

Si la sucursal no contara con representante debidamente facultado, no sería posible que realice actividad económica legítima y vinculante para con la sociedad 
principal, ya que ésta actúa por encargo de aquella, según las facultades y autorizaciones que se le deleguen al momento de su nombramiento (Flury, 2009, p. 109).

Dado que el representante goza cuando menos de las facultades necesarias para obligar a la sociedad principal por las operaciones que realice y de las generarles de representación procesal que exigen las normas vigentes, podemos señalar que por el solo hecho de tener la designación de representante legal permanente, de manera automática tendrá las facultades mínimas y la capacidad legal de actuar con éstas.

En cuanto a las facultades necesarias para obligar a la sociedad principal por las operaciones que realice la sucursal, es necesario concordar tal disposición con lo señalado por el artículo 400 de la Ley $\mathrm{N}^{\circ} 26887$, el mismo que establece que el representante legal permanente de una sucursal se rige por las normas establecidas en esta ley para el gerente general de una sociedad, en cuanto resulten aplicables. Al término de su representación por cualquier causa y salvo que la sociedad principal tenga nombrado un sustituto, debe designar de inmediato un representante legal permanente.

De conformidad con dicha disposición, las facultades con las que cuenta el representante legal permanente son aquellas autorizadas por ley (Ley $\mathrm{N}^{\circ}$ 26887) al gerente general, las mismas que se encuentran detalladas en el artículo $188^{\circ}$ del mismo dispositivo y que detallamos a continuación:

Artículo 188.- Atribuciones del gerente

Las atribuciones del gerente se establecerán en el estatuto, al ser nombrado o por acto posterior.

Salvo disposición distinta del estatuto o acuerdo expreso de la junta general o del directorio, se presume que el gerente general goza de las siguientes atribuciones: 1. Celebrar y ejecutar los actos y contratos ordinarios correspondientes al objeto social;

2. Representar a la sociedad, con las facultades generales y especiales previstas en el Código Procesal Civil;

3. Asistir, con voz, pero sin voto, a las sesiones del directorio, salvo que éste acuerde sesionar de manera reservada;

4. Asistir, con voz, pero sin voto, a las sesiones de la junta general, salvo que ésta decida en contrario; 
5. Expedir constancias y certificaciones respecto del contenido de los libros y registros de la sociedad; $\mathrm{y}$,

6. Actuar como secretario de las juntas de accionistas y del directorio.

Cabría aclarar que, respecto de las facultades de los numerales 3, 4 y 6, éstas no son aplicables al representante legal permanente de la sucursal toda vez que ésta, por su propia naturaleza, no cuenta con tales órganos de gobierno (directorio y junta general de accionistas).

Asimismo, en cuanto a las facultades generales de representación procesal, la designación inviste al representante legal permanente de las facultades de representación contenidas en el artículo $74^{\circ}$ del TUO del Código Procesal Civil ${ }^{4}$ (Resolución Ministerial $\mathrm{N}^{\circ} 010-93-J U S$ ), el mismo que confiere atribuciones y potestades generales, mas no aquellas para las que se requiera facultades expresas.

La Ley $N^{\circ} 26887$ prevé que se otorgue facultades expresas al representante legal permanente, cuyo otorgamiento debe ser detallado y que le permitirán la mejor actuación en el ejercicio de sus funciones, lo que ciertamente se encuentra directamente relacionado con los límites de responsabilidad que se asumirá pues, de conformidad con el artículo $13^{\circ}$ de la Ley: Quienes no están autorizados para ejercer la representación de la sociedad no la obligan con sus actos, aunque los celebren en nombre de ella.

La responsabilidad civil o penal por tales actos recae exclusivamente sobre sus autores.

A propósito de la responsabilidad debemos comentar que como las sucursales no son personas jurídicas distintas de la sociedad matriz, las obligaciones que contraiga la sucursal se extienden a la principal, la que responde en forma ilimitada por dichos actos, siendo nulo todo pacto en contrario, de conformidad con lo establecido por el artículo 397 de la Ley $N^{\circ} 26887$ :

Artículo 397.- Responsabilidad de la principal

\footnotetext{
${ }^{4}$ Artículo 74.- La representación judicial confiere al representante las atribuciones y potestades generales que corresponden al representado, salvo aquellas para las que la ley exige facultades expresas. La representación se entiende otorgada para todo el proceso, incluso para la ejecución de la sentencia y el cobro de costas y costos, legitimando al representante para su intervención en el proceso y realización de todos los actos del mismo, salvo aquellos que requieran la intervención personal y directa del representado.
} 
La sociedad principal responde por las obligaciones de la sucursal. Es nulo todo pacto en contrario.

No obstante, hay algunas consideraciones relacionadas con la responsabilidad del representante legal permanente que pasamos a comentar seguidamente:

a) La Ley no exige que el representante legal permanente sea una persona que resida en el país, lo que no parecería brindar el mínimo de seguridad jurídica que se requeriría para resguardar el cumplimiento de las obligaciones de la sucursal ante terceros; sin perjuicio de que exista la posibilidad de exigir el cumplimiento a la matriz o principal. Al no residir el representante legal en el país, no hay una cabeza visible ante quien expresar el reclamo o la pretensión.

b) Que la responsabilidad es solidaria entre matriz y representante legal permanente, pero en la práctica la exigibilidad del cumplimiento de obligaciones a la matriz resulta mucho más difícil, lenta y onerosa que la exigibilidad al representante legal permanente, lo que vinculado con el literal precedente nos permite afirmar que el riesgo de tener que requerir el cumplimiento a la matriz se incrementa si el representante legal permanente no reside en el país.

c) La designación de un representante legal permanente no deja de ser una designación de un cargo de confianza de la matriz pues, ciertamente tal representante asumirá funciones con cierta autonomía en el marco de las facultades otorgadas por la principal. En ese sentido, entendemos, sobre todo al inicio de las operaciones de la sucursal, que sea posible que la persona nombrada como representante legal permanente, en la medida que sea de confianza de la matriz, resida en cualquier lugar del mundo, lo que es avalado por nuestra legislación con la finalidad de darle a las empresas extranjeras y a la inversión extranjera en general mayor flexibilidad para su ingreso al país; sin embargo esto no deja de resultar en una suerte de desprotección para los terceros acreedores de la sucursal cuando en lugar de dirigirse directamente contra la sucursal deban hacerlo a la matriz o principal ante la ausencia del representante legal permanente en territorio peruano.

d) La renuncia del representante legal permanente no es tan ágil como su nombramiento. En efecto, tal como se puede apreciar de las disposiciones 
pertinentes de la Ley $\mathrm{N}^{\circ} 26887$, el nombramiento del representante legal permanente se realiza incorporando tal nombramiento en el acuerdo de establecimiento de la sucursal, e incluyendo las facultades que se le otorgan. Ese nombramiento no requiere de aceptación del representante.

No obstante, ante cualquier situación en la que el representante legal permanente quisiera renunciar a la representación otorgada y esta no fuera aceptada por la matriz, la renuncia tendría que seguir los mecanismos que se dicta en tal situación para el gerente general pues, como hemos señalado, el artículo $400^{\circ}$ de la Ley $\mathrm{N}^{\circ} 26887$ establece que el representante legal permanente se rige por las normas establecidas para el gerente general de una sociedad, en cuanto resulten aplicables.

En ese sentido, ante una situación en la que el representante legal permanente decidiera renunciar y su renuncia no fuera aceptada, se vería en la necesidad de seguir el procedimiento previsto para la renuncia establecido en el articulo $46^{\circ}$ del Reglamento de Inscripciones del Registro de Personas Jurídicas (Resolución del Superintendente Nacional de los Registros Públicos No 038-2013-SUNARP-SN), el mismo que establece que para la inscripción de la renuncia de un representante o integrante de un órgano deberá presentarse la solicitud del renunciante con firma certificada por notario, acompañada de la carta de renuncia con la constancia de haber sido recibida por la persona jurídica, en original, en copia certificada notarialmente o autenticada por fedatario de cualquier Oficina Registral que integre algún órgano desconcentrado de la Superintendencia Nacional de los Registros Públicos.

La aplicación de tal disposición supondría la recepción de la carta de renuncia en el domicilio de la matriz, para lo cual será necesario contar con fe de entrega notarial del documento y las legalizaciones correspondientes, de tal forma que se le dote a la entrega en el extranjero de validez en el Perú y sea posible la acreditación ante el registro público de haber seguido tal procedimiento. Sin perjuicio de que existe el mecanismo para hacerlo, lo cierto es que, en este supuesto, la renuncia resulta más lenta y onerosa que el acto de designación que ni siquiera implicó la aceptación del poder por parte del representante legal permanente.

Cabe señalar que, si en el ínterin la sociedad extranjera no designa a un representante legal permanente, de conformidad con lo señalado por el artículo 401 de la Ley $\mathrm{N}^{\circ} 26887$, si transcurren noventa días de vacancia del cargo sin que la sociedad 
principal haya acreditado un nuevo representante legal permanente, el Registro, a petición de parte con legítimo interés económico, cancela la inscripción de la sucursal. La cancelación de la inscripción de la sucursal no afecta a la responsabilidad de la sociedad principal por las obligaciones de aquella, inclusive por los daños y perjuicios que haya ocasionado la falta de nombramiento de representante legal permanente.

Finalmente, cabe señalar que, en la medida que las normas establecidas para el gerente general de una sociedad le son aplicables al representante legal permanente, este deberá asumir las responsabilidades en el marco de lo establecido por el artículo 190 de la Ley $\mathrm{N}^{\circ}$ 26887) el mismo que establece que el gerente responde ante la sociedad, los accionistas y terceros, por los daños y perjuicios que ocasione por el incumplimiento de sus obligaciones, dolo, abuso de facultades y negligencia grave.

En efecto podría suceder que el incumplimiento de las obligaciones por parte del representante, no corresponda a decisiones de la matriz y esta pueda accionar contra el representante.

En ese sentido, como bien señala Hundskopf (2015, p. 233) la principal o matriz podrá iniciar las pretensiones sociales e individuales de responsabilidad que correspondan.

\subsection{Sobre el sometimiento de la matriz a las leyes del Perú}

Nuestra legislación societaria exige que en el acuerdo de la matriz para constituir la sucursal en el Perú conste su sometimiento a las leyes del Perú, redacción que ha generado opiniones entre los juristas nacionales respecto de cuál es el alcance de dicho sometimiento, o planteado de otro modo: ¿quién se somete a las leyes del Perú? ¿Es el representante legal permanente, la sucursal o la matriz? ¿O los tres al mismo tiempo? ¿Es acaso esta diferenciación intrascendente para efectos prácticos?

Repasando la lectura del inciso 3 del artículo 403 de la Ley $\mathrm{N}^{\circ} 26887$, apreciaremos que la interrogante no carece de importancia: El acuerdo de establecer la sucursal en el Perú, adoptado por el órgano social competente de la sociedad, que indique: (...) la designación de por lo menos un representante legal permanente en el país; los poderes que le confiere; y su sometimiento a las leyes del Perú para responder por las obligaciones que contraiga la sucursal en el país. 
Los casos de confusión no han sido escasos en el pasado, tal como lo hace notar Hundsfopf $(2015$, p.225) al citar la resolución del Tribunal Registral 1563-2013SUNARP-TR-L de 25 de setiembre de 2013 en la que, entre otros temas, se aborda el sometimiento a las leyes del Perú. Al respecto se indica en dicha resolución que “... podemos apreciar que en el acta de directorio del 24/10/2012, inserta en la citada escritura pública del 21/11/2012, se señala que: "la sucursal se someterá a las leyes del Perú"; sin embargo, el inciso 3 de la Ley General de Sociedades anteriormente transcrito, al exigir que en el documento conste “... su sometimiento a las leyes del Perú para responder por las obligaciones que contraiga la sucursal en el país" se refiere a la principal o matriz, es decir, que el sometimiento a las leyes del Perú sea de esta última.

Como vemos, en este caso, la matriz argentina asumió que quien se sometería a las leyes del Perú sería su sucursal peruana y no la matriz argentina, lo que puede tener lógica para cualquier extranjero, ya que, en la práctica, someter a una empresa a las leyes de otro país parece ser una tarea complicada y por demás onerosa, tal como hemos podido ver en tramos precedentes de este estudio.

Un caso más reciente que hemos podido apreciar es el del título 2015-00971768 en el que la matriz venezolana indicó en su acuerdo que quien se sometería a las leyes del Perú sería el representante legal permanente. Al respecto el registrador observó indicando expresamente: "Téngase en cuenta que, el acuerdo de constitución de la sucursal debe contener el sometimiento de la sociedad extranjera a las leyes del Perú para responder por las obligaciones que contraiga la sucursal en el país”.

Podemos apreciar entonces que, es en la vía registral en donde nuestra interrogante toma fuerza y es también en esa misma sede en donde el operador registral la resuelve concluyendo directamente que quien queda sometida a la legislación tiene que ser la matriz, sin embargo, se limita a indicarnos su conclusión mas no su razonamiento.

Es por ello que para dar respuesta a nuestra interrogante, primero hemos querido interpretar el texto de la norma desde el punto de vista lingüístico, así podemos apreciar que cuando el texto indica la frase "su sometimiento" lo hace inmediatamente antes de la frase "designación de por lo menos un representante legal permanente en el país; los poderes que le confiere; " seguido de la conjunción “ $y$ " que implica enlace, lo que debería entonces llevarnos a concluir de la lectura corrida, que se está solicitando la designación de un representante, sus poderes y su sometimiento a las leyes del Perú. 
Ante esta primera conclusión, decidimos analizar la opinión que respecto de este asunto tiene Tori Vargas (2006) quien señala que, si bien nuestra legislación dota a las sucursales de cierto margen de autonomía, no debe perderse de vista que se trata de un ente jurídico único, que como tal comparte un mismo patrimonio, a pesar de que para fines prácticos sea necesario asignar a la sucursal bienes o derechos específicos (p. 317). Así pues, las obligaciones contraídas por la sucursal no dejan de ser de la sociedad (matriz); y, por tanto, quedan protegidas con el patrimonio de esta, por ello, asumimos, quien debe quedar obligada es la matriz.

También creemos que el legislador debe haberse efectuado la siguiente pregunta: ¿es más conveniente, para efectos de generar confianza en los acreedores peruanos, que se someta a la legislación peruana solo al representante legal o a la sucursal? ¿no será aún mejor que se someta a la matriz, pues finalmente su sucursal no es sino un brazo o extensión de esta?

Creemos, siguiendo a Tori Vargas (2006), que en base al razonamiento antes expuesto, lo que el legislador habría pretendido es resguardar la confianza de quienes contratan con un sujeto (la sucursal) que consideran parte de un conjunto indivisible, ya que quien contrata con una sucursal peruana, asume (o tiene la confianza) que esta se encuentra respaldada por el grupo al cual pertenece, es decir, por su matriz, siendo por ello lo más práctico que sea ésta la que quede obligada frente a cualquier tercero que contrate con ella. (p. 311)

Cabe señalar también que, si bien es cierto (de acuerdo a lo recientemente concluido) que es la casa matriz la que queda sometida a las leyes del Perú, no es menos cierto que, por ese mismo hecho, la matriz puede argumentar la eventual ineficacia de los actos jurídicos desarrollados por su representante legal permanente cuando éste se ha excedido en sus facultades, lo que podría llevar a concluir que finalmente la matriz podría (en virtud a lo dispuesto por nuestra propia legislación) limitar la acción de responsabilidad contra ella a la responsabilidad personal de su representante legal en el Perú, al ser los actos del representante ineficaces de acuerdo a nuestro Código Civil (Decreto Legislativo N²95).

\subsection{Sobre la reorganización de la sucursal}

El Artículo $395^{\circ}$ de la Ley $\mathrm{N}^{\circ} 26887$ contempla la reorganización de la sucursal de una sociedad constituida en el extranjero señalando que: la sucursal establecida en el Perú de 
una sociedad constituida en el extranjero puede reorganizarse; así como ser transformada para constituirse en el Perú adoptando alguna de las formas societarias reguladas por esta ley, cumpliendo los requisitos legales exigidos para ello y formalizando su inscripción en el Registro.

El artículo $140^{\circ}$ del Reglamento del Registro de Sociedades (Resolución del Superintendente Nacional de los Registros Públicos N²00-2001-SUNARP-SN) señala que, para efectos registrales, la sucursal en el Perú de una sociedad constituida en el extranjero, a que se refiere el artículo $395^{\circ}$ de la Ley, puede reorganizarse, por decisión de la sociedad matriz, mediante las siguientes formas:

a) Transformación de la sucursal;

b) Reorganización simple;

c) Fusión de absorción en la cual la sucursal absorbe a una o más sociedades;

d) Escisión de patrimonio de la sucursal, ya sea mediante la transferencia de uno o más bloques patrimoniales a una o más sociedades existentes o que se constituyan para al efecto o la transferencia de bloques patrimoniales a favor de otra sucursal;

e) Cualquier otra operación en que se combinen, transformaciones, fusiones o escisiones.

Tal como se puede apreciar, en principio cualquier forma de reorganización involucraría una decisión de la matriz y afectaría su patrimonio; sin embargo, como bien señala Morales Acosta y Castillo Wong (2002), la Ley N. ${ }^{\circ} 26887$ permite que la transformación se dirija únicamente a la sucursal sin que sea necesaria la transformación de la matriz o principal:

Si bien lo normal sería que toda la sociedad (matriz y sucursal) se transforme, empero, la novedad introducida por la Ley General de Sociedades consiste precisamente en permitir que continúe la personalidad jurídica de la matriz, sin que se transforme toda la matriz, sino solo una parte de ella, la cual continua en el resultado de la transformación, solo que con la independencia de la matriz constituida en el exterior. (p. 36)

Desde nuestro punto de vista, este esquema es viable gracias a otra ficción jurídica. Como hemos visto a lo largo del presente documento la sucursal es una ficción 
jurídica que implica la extensión de la matriz a través de un esquema en el que se extiende su personería de jurídica más allá de su ámbito territorial. La sucursal por sí misma no cuenta con personería jurídica, con lo cual, en principio no podría ser materia de reorganización en los parámetros que establece el artículo $333^{\circ}$ de la Ley General de Sociedades (Ley $\mathrm{N}^{\circ} 26887$ ) pues, la reorganización está prevista entre personas jurídicas constituidas en el Perú. No solo entidades con personería jurídica, sino además constituidas en el Perú.

Artículo 333.- Casos de transformación

Las sociedades reguladas por esta ley pueden transformarse en cualquier otra clase de sociedad o persona jurídica contemplada en las leyes del Perú.

Cuando la ley no lo impida, cualquier persona jurídica constituida en el Perú puede transformarse en alguna de las sociedades reguladas por esta ley.

La transformación no entraña cambio de la personalidad jurídica.

Esta ficción jurídica le permite a la sucursal adaptarse a cualquiera de las formas societarias que prevé la Ley, adquiriendo así formalmente personalidad jurídica autónoma de su matriz. No obstante, como señala Morales Acosta y Castillo Wong (2005) seguirá siendo en esencia la misma sucursal que ha cambiado en la forma de organizar jurídicamente su patrimonio, para transformarse en una sociedad constituida bajo nuestro régimen legal (p. 37).

En efecto, con la transformación, no se produce transferencia ni sucesión patrimonial sobre los bienes de la sucursal objeto de la transformación. En ese sentido mantiene identidad, RUC, planilla de trabajadores, giro, probablemente al representante legal etc. Lo único que sucede es que por decisión de la matriz la sucursal obtendrá personería jurídica bajo el marco de alguna de las modalidades societarias previstas en la Ley.

Como hemos señalado, la Ley General de Sociedades también prevé que la reorganización involucre parte o todo el patrimonio del principal no asignado a la sucursal, en cuyo caso se aplican las disposiciones del artículo 406 de la Ley (Ley $\mathrm{N}^{\circ} 26887$ ) que rigen la fusión y escisión de una sociedad extranjera con sucursal en el Perú. 
En los supuestos de fusión, la sociedad extranjera que adquiere el bloque patrimonial, ya sea por absorción o incorporación, asumirá las sucursales de las sociedades que se extinguen salvo pacto en contrario.

Para la inscripción del nuevo titular de la sucursal se requerirá acreditar la entrada en vigencia de la fusión en el lugar de la sociedad principal; el nombre, el lugar de constitución y domicilio de la sociedad principal absorbente o incorporante y que ella pueda tener sucursales en otro país.

Asimismo, la sociedad que adquiere el bloque patrimonial en la escisión, asumirá las sucursales de las sociedades que se escindan. El cambio de titularidad en este caso también requerirá de la inscripción en el registro acompañada de la documentación que acredite que la escisión ha entrado en vigencia en el lugar de la respectiva sociedad principal; el nombre, lugar de constitución y domicilio de la sociedad beneficiaria del bloque patrimonial que incluye el patrimonio de la sucursal y que ella puede tener sucursales en otro país (Hundskopf, 2012, p. 340).

Desde nuestro punto de vista, la reorganización de la sucursal está limitada únicamente a la modalidad de transformación. La fusión y escisión a la que hace referencia el Reglamento, tal como señala Castle Álvarez (2005), no consiste en una fusión de la sucursal de un bloque patrimonial (p. 1267). En realidad, se trata de la decisión de la matriz de fusionarse, lo que sucederá bajo la legislación de la principal o matriz y por consiguiente se regirá por las disposiciones propias de su país. En ese sentido la regulación dispuesta en el reglamento pierde sentido.

Continúa Castle Álvarez (2005) señalando que, lo mismo sucede con la escisión, la decisión de escisión es de la principal, la que escinde parte de su patrimonio, que coincide con el patrimonio con el que cuenta la sucursal (p. 1267), en cuyo caso corresponderá inscribir en el Perú únicamente la titularidad de los bienes registrables involucrados.

Tal como se puede apreciar, la legislación vigente brinda un marco legal para que las empresas extranjeras extiendan sus operaciones al Perú a través del establecimiento de sucursales. No obstante, hay aspectos que aún son objeto de interpretación o que incluso evidencian falta de precisión y hasta errores en la ley o en la reglamentación correspondiente. Lo cierto es que, al establecerse una sucursal, en su desarrollo o incluso 
en la decisión de transformarse y constituirse en una empresa peruana, hay una serie de factores favorables y desfavorables tanto para el empresario como para los terceros que se relacionen con ella que deberán sopesarse para tomar la decisión más acertada. 


\section{CONCLUSIONES}

Entre los requisitos exigidos por la Ley General de Sociedades (Ley $\mathrm{N}^{\circ}$ 26887), para el establecimiento de una sucursal, hay algunos que, si bien son similares a los correspondientes a las demás modalidades societarias comprendidas en la citada Ley, adquieren connotaciones distintas o diferenciadas específicamente para el caso de las sucursales.

- Capital asignado no debe asimilarse al concepto de capital social. Para el capital asignado no existe un título representativo que lo acredite ya que la ley no lo exige.

- El capital asignado no es una garantía "inmediata o automática" para los acreedores que pretendan cobrarse con este pues, los fondos no necesariamente se encontrarán en el país debido a que no es necesario acreditarlo al momento de establecerse la sucursal en el Perú.

- En el acuerdo de establecimiento de la sucursal es necesario fijar domicilio, el mismo que corresponderá a una zona geográfica distinta al de la principal. Para la determinación de tal domicilio se evidencia una contradicción entre lo establecido en el artículo 21 y 403 de la Ley pues por un lado se establece la asignación de domicilio como requisito para el establecimiento de la sucursal y, por otro lado, se establece que si no se señala domicilio se presume Lima.

- La indicación del domicilio de la sucursal en su denominación complementa la delimitación de la zona geográfica pues, evidentemente, el registro público no admitirá la inscripción en una misma zona registral de dos sucursales bajo la misma denominación.

- La inexistencia de personería jurídica propia o independiente de la principal, es el sustento para que la sucursal no tenga una denominación propia, sino que incluso su denominación sea una extensión de su principal, pues en la sucursal y principal se identifica al mismo sujeto de derechos.

- Cuando preexiste una sociedad peruana con la misma denominación que la que pretende registrar la sucursal, la salida más viable para efectos de la inscripción 
registral o formalización en el Perú de la sociedad extranjera es la constitución de una filial o subsidiaria

- La Ley no exige que el representante legal permanente sea una persona que resida en el país, lo que no parecería brindar el mínimo de seguridad jurídica que se requeriría para resguardar el cumplimiento de las obligaciones de la sucursal ante terceros sin perjuicio de que exista la posibilidad de exigir el cumplimiento a la matriz o principal.

- La responsabilidad es solidaria entre matriz y representante legal permanente, pero en la práctica la exigibilidad del cumplimiento de obligaciones a la matriz resulta mucho más difícil, lenta y onerosa que la exigibilidad al representante legal permanente.

- La ley no exige que el representante legal permanente resida en el Perú lo que no deja de resultar en una suerte de desprotección para los terceros acreedores de la sucursal cuando en lugar de dirigirse directamente contra la sucursal deban hacerlo a la matriz o principal ante la ausencia del representante legal permanente en territorio peruano.

- La renuncia del representante legal permanente no es tan ágil como su nombramiento pues deberá seguir el procedimiento previsto para la renuncia establecido en el articulo $46^{\circ}$ del Reglamento de Inscripciones del Registro de Personas Jurídicas.

- Si bien es cierto que es la casa matriz la que queda sometida a las leyes del Perú, no es menos cierto que, por ese mismo hecho, la matriz puede argumentar la eventual ineficacia de los actos jurídicos desarrollados por su representante legal permanente cuando éste se ha excedido en sus facultades, lo que podría llevar a concluir que finalmente la matriz podría limitar la acción de responsabilidad contra ella a la responsabilidad personal de su representante legal en el Perú.

- La reorganización en nuestra legislación está prevista solo para empresas constituidas en el Perú, sin embargo, la ley ha establecido expresamente la posibilidad de transformación de la sucursal, la que parecería ser la única modalidad de reorganización aplicable en la práctica a la sucursal pues, cualquier otra forma de reorganización involucraría una decisión de la matriz. 


\section{REFERENCIAS}

Beaumont Callirgos, R. (2001). Las sucursales: caracterización e innovaciones. Revista Peruana de Derecho de la Empresa, 16(52), 81-98.

Castle Álvarez, P. (2005). Las sucursales en la Ley General de Sociedades Peruana. En Instituto Peruano de Derecho Mercantil (Ed.), Tratado de Derecho Mercantil (2. ${ }^{a}$ ed., T. 1, pp. 1227-1271). Lima: Gaceta Jurídica

Echaiz Moreno, D. (2012). Manual societario (2. a ed.). Lima. Grijley.

Estrada Espinoza, M. y Olórtegui Azato, A. (2012). La capacidad máxima de contratación de las sucursales de empresa extranjeras. Actualidad Jurídica (221), 331-337.

Flury, H. (2009). Las sucursales en el derecho societario del Perú: una aproximación práctica. Lima. Turecuerdo.

Hundskopf, O. (2012). Manual de derecho societario (2. ${ }^{a}$ ed.) Lima: Gaceta Jurídica.

Hundskopf, O. (2015). Derecho comercial: temas societarios (T. 14). Universidad de Lima.

Ley N. ${ }^{\circ}$ 26702, Ley General del Sistema Financiero y del Sistema de Seguros, y Orgánica de la Superintendencia de Banca y Seguros (09 de diciembre de 1996). Recuperado del sitio de internet del Sistema Peruano de Información Jurídica: http://spij.minjus.gob.pe/web/main.asp

Ley N. ${ }^{\circ}$ 26887, Ley General de Sociedades. (09 de diciembre de 1997). Recuperado del sitio de internet del Sistema Peruano de Información Jurídica: http://spij.minjus.gob.pe/CLP/contenidos.dll?f=templates\&fn=default$\underline{\text { leyes.htm\&vid=Ciclope:CLPdecleyes }}$

Morales Acosta, A. y Castillo Wong, M. (2002). Implicancias jurídicas de la transformación de la sucursal de una sociedad constituida en el extranjero. Revista Peruana de Derecho de la Empresa, 17(54), 27-54.

Reaño Azpilcueta, R. (2010). Tributación aduanera. Lima: Palestra.

Resolución N. ${ }^{\circ}$ 200-2001-SUNARP-SN. Reglamento del Registro de Sociedades. (27 de julio del 2001). Recuperado del sitio de internet de la Superintendencia Nacional de Registros Públicos: https://www.sunarp.gob.pe/publi_RSociedades00.asp.

Resolución del Superintendente Nacional de los Registros Públicos Nº 038-2013-SUNARPSN. Reglamento de Inscripciones del Registro de Personas Jurídicas (19 de febrero del 2013). Recuperado del sitio de internet del Sistema Peruano de Información Jurídica: http://spij.minjus.gob.pe/web/main.asp

Resolución Ministerial Nº 010-93-JUS. Texto Único Ordenado del Código Procesal Civil promulgado por Decreto Legislativo 768. (22 de abril de 1993). Recuperado del sitio de internet del Sistema Peruano de Información Jurídica. http://spij.minjus.gob.pe/web/main.asp 
Sucursales y las filiales: dos conceptos diferentes. (22 de junio del 2015). Recuperado de http://www.negopolis.com.pe/sucursales-y-las-filiales-dos-conceptos-diferentes/

Tori Vargas, F. (2006). Responsabilidad de la casa matriz no domiciliada por el impuesto a la renta de cargo de su sucursal peruana. En Instituto Peruano de Derecho Tributario, IX Jornadas Nacionales de Derecho Tributario. Recuperado de http://www.ipdt.org/editor/docs/15_IXJorIPDT_FTV.pdf 


\section{BIBLIOGRAFÍA}

Abrir una sucursal. (18 de junio del 2013). Recuperado de http://emprendedor.pe/primera-empresa/889-abrir-una-sucursal.html/

Aguirre Moreno, K. (2013). Calificación registral de los poderes otorgados por sociedades extranjeras. Dialogo con la Jurisprudencia, (178), pp.192-196.

Calderón Aguilar, L. y Bernal Rojas, J. (2002). Tratamiento tributario de las sucursales. Actualidad Empresarial, (21), pp. I1- I8.

Dávila Canicoba, J. (2004) Las sucursales en el Perú. Actualidad Empresarial, (73), pp. vii 1 -vii 2.

Establecimiento de sucursales de sociedades peruanas y extranjeras. (2012). Recuperado de $\quad$ http://www.caballerobustamante.com.pe/plantilla/2012/Establecimientosucursales-sociedades.pdf 